\title{
PRESTRESSED HOMOGENIOUS STEEL BEAMS STRENGTHENED IN COMPRESSION AND TENSION - A HYPOTHETICAL CASE STUDY
}

\author{
Ravindra Vipparthy ${ }^{1}$, Markandeya Raju Ponnada ${ }^{2}$ \\ ${ }^{1}$ Professor of Civil Engineering, Jawaharlal Nehru Technological University Kakinada, - 533 003, (A.P), INDIA. \\ ${ }^{2}$ Professor of Civil Engineering, MaharajVijayaramGajapathi Raj College of Engineering, Vijayaram Nagar Campus, \\ Chintalavalasa, VIZIANAGARAM - 535 005, (A.P), INDIA. \\ e-mail : markandeyaraju@gmail.com, mobile : 9440528403
}

\begin{abstract}
The technology of prestressing steel structures is relatively an old frontier in the field of structural engineering. In spite of having many advantages over prestressed concrete, prestressed steel has not been popular in academics as well as in industry. This paper is an attempt to study the variation of Load carrying capacity for same Force Factor (FF), same Eccentricity Ratio (ER), same span and same cross-section strengthened in compression and tension.ISWB600@145 was considered for study for a span of $8 \mathrm{~m}$ to 16m. Four types of cross-sections are considered for comparison, namely 1) I-section, 2) I-section laterally strengthened in compression and tension by welding four angle sections, 3) I-section laterally strengthened in compression alone by welding two angle sections, 4) compound girder formed by welding a plate to the top flange of an I-section. A straight tendon configuration over the whole span is considered for study. The non-dimensional design parameters like FF and ER were considered as 0.4 and 0.5 respectively. The \% increase in the load carrying capacity for each case was calculated with respect to the beam without prestressing. It has been observed that welding a plate to the top flange of an I-section can increase the load carrying capacity of the I-section up to $80 \%$ when prestressed. In other words, the material of the cross-section is effectively utilized when an unsymetrical I-section is prestressed.
\end{abstract}

Keywords: External prestressing, lateral strengthening, tendon configurations, metallic carpentry, optimum parameters, stress distribution, net area, allowable span, permissible eccentricity.

\section{INTRODUCTION}

\subsection{GENERAL}

${ }^{1}$ The concept of prestressing steel structures has only recently been widely reconsidered, despite a long and successful history of prestressing concrete members. The term prestressed steel means 'a steel member subjected to a concentric or eccentric force so that the state of stress in the member due to this force and any other loading is within permissible limit'.Prestressing is a process by which opposite stresses are introduced in the structure before the structure is put to its actual use. Opposite stresses are introduced in the structure by initial application of external forces controlled in magnitude and direction to counter act the development of undesirable stresses in the beam due to working load. Prestressing of I-beam can be done in any one of the following two basic ways. One is to place tendon below the centroid of beam (inside beam) and attach them at each end of beam and other is to place tendon below beam fiber in tension (outside the beam).First prestressing force is applied creating two normal stress components, axial and bending. Top and bottom flanges are subjected to tension and compression respectively. This distribution of stresses is opposite to that caused by downward applied load. When transverse loads (including both dead and live loads) are applied, resulting bending stresses add to stresses due to prestressing to give final combined stress distribution.

${ }^{3}$ Ideal stress distribution due to prestressing would be one in which top and bottom fiber stresses are equal. If prestressed beams are designed of symmetrical cross sections, bottom chord will always remain under stressed,where as compressive stresses in the top chord attains its design value. Theoretically an infinitely large value of eccentricity would be necessary while prestressing force approaches zero, to obtain the above distribution.In order to utilize material of beam cross section to full capacity, the cross section should be designed unsymmetrical so that the center of the cross section gets displaced towards top flange. After prestressing, when an external load is applied to beam, stresses in top and bottom fibers are nearly equal to the design strength of the material. Thus an important feature is that for a cross section, which is well proportioned, we have equal stress distribution in top and bottom fibers of beam. This arrangement has a great deal of promise for economical construction. The assumptions based on which the methodology for design of prestressed steel beams are designed are as follows.

1. Steel is a homogeneous, elastic and isotropic.

2. Within working stresses, steel obeys hooks law.

3. Plane section before bending remains plain even after bending.

4. Small amount of creep that occurs under sustained loading is ignored.

5. Longitudinal fibers are free to expand and contract.

6. Any change in loading of member results in a change of stress in steel only. The prestressing tendon is only to impart and maintain prestress in the steel.

7. Welding is safe under the combined action of prestressing force and external loads. 
8. There is no lateral buckling under the combined action of prestressing force and the external loads.

9. There is no loss of prestress in the prestressing steel at any stage.

10. The net deflection is the difference of downward deflection due to loads on the beam and the camber due to prestressing force.

11. The prestressing tendon is only to impart and maintain prestress in the steel

1.1.1 ${ }^{5}$ Advantages of prestressed steel beams

1. Lighter and slender members are possible by using prestressed steel when compared with unprestressed steel beams.

2. The whole cross section is effective in prestressed steel beam. But in unprestressed steel beams a lot of material is wasted.

3. Use of high strength steel is permitted in prestressed steel members, which contributes to improved durability under aggressive environmental conditions.

4. Prestressed steel beams deflect appreciably before ultimate failure when compared with un-prestressed steel members thereby giving ample warning before collapse.

5. The economic advantage in prestressed steel structure when compared with un-prestressed steel structure is about $15 \%$ taking into account the cost of cables and the technology of prestressing.

6. Standard components required for prestressed steel beams can be quickly and easily fabricated when compared to those of prestressed concrete beams.

7. Fatigue strength of prestressed steel member is better when compared with that of un-prestressed steel member and prestressed concrete member.

8. Hence it can be recommended for dynamically loaded structures.

9. The external prestressing technique can be used to improve the load carrying capacity of existing un-prestressed steel beams. It is not always possible in case of R.C.C beams.

10. We can improve the strength steadily by adding multistage prestressing and acquire the required load carrying capacity.

11. Prestressed steel beams are ideally suitable against prestressed concrete beams for temporary bridge construction because the former can be reused.

1.1.2 ${ }^{5}$ Disadvantages of prestressed steel beams:

1. Longer spans are not recommended to avoid possible buckling.

2. Externally prestressed members can easily be damaged.

3. The availability of builders and engineers experienced with the technique of external prestressing of steel is scanty.

4. Initial equipment cost is very high.

5. Prestressing tendons are brittle as high strength steel is used.

1.1.3 ${ }^{5}$ Applications of prestressed steel beams

Some of the typical applications where external tendonsand hence prestressed steel beams are feasible, practical and economical are as follows:

1. Rehabilitation of existing steel structures.

2. Under slung structures

3. Precast segmental construction

4. Simple and continuous spans.
5. Incremental launching procedures in particular centric prestressing

6. Temporary bridge construction

7. To improve the load endurance of existing bridges

\subsection{LITERATURE REVIEW}

A keynote address by Guptha3 on prestressed steel structures in a conference on "Modern trends in steel structures " briefs the behavior of prestressed steel structures like prestressed steel frames, prestressed steel trusses etc. Optimum parameters for design of prestressed steel structures were listed out towards the end.Brodka and Klobukovki4 developed ATOM bridge construction method to maximize the economic effect and improve the construction convenience of Prestressed steel bridges. The demerits of the existing method and the methodology proposed by the authors were discussed. The method emphasizes the importance of temporary bridge construction.

\subsection{OBJECTIVE}

In spite of having many advantages, prestressed steel construction is not popular in the field of metallic carpentry. The possible reasons are

Unlike prestressed concrete, the subject is not included in the curriculum of universities

Prestressing of steel structures is done by external prestressing technique, which has many technical and other problems.

This paper is an attempt to encourage prestressing of steel beams by comparing them with un-prestressed beams. A study on the variation of Load carrying capacity for same Force Factor (FF=Prestress/Permissible bending Compressive stress), same Eccentricity Ratio (ER = eccentricity/Total Depth), same span and same cross-section strengthened in compression and tension was conducted and results were discussed.

\subsection{SCOPE OF PRESENT STUDY}

ISWB600@145 was considered for study for a span of $8 \mathrm{~m}$. Four types of cross-sections are considered for comparison, namely 1) I-section, 2) I-section laterally strengthened in compression and tension by welding four angle sections (Fig. 1), 3) I-section laterally strengthened in compression alone by welding two angle sections (Fig. 2), 4) Compound girder formed by welding a plate to the top flange of an I-section (Fig. 3). A straight tendon configuration over the whole span is considered for study. The non-dimensional design parameters like FF and ER were considered as 0.4 and 0.5 respectively. The \% increase in the load carrying capacity for each case was calculated with respect to the beam without prestressing.

\section{ANALYTICAL PROCEDURE}

Consider an steel I-beam prestressed with a constant eccentric prestressing force of ' $p$ ' at a distance ' $e$ ' from neutral axes of the beam. The following four cases have been considered for the purpose of analysis.

CASE1:ISJ 
CASE 2:ISJ STRENGTHED IN COMPRESSION AND TENSION BY WELDING FOUR ANGLE SECTIONS CASE 3:ISJ STRENGTHED IN COMPRESSION AND TENSION BY WELDING TWO ANGLE SECTIONS CASE 4: ISJ STRENGTHED IN COMPRESSION BY WELDING A PLATE

Various parameters are determined and compared with their permissible limits from their respective formulae derived in the following sections. The notations for different dimensions of an I-section are shown in Figure 4 to Figure 7. The general notation for the variables is shown in Appendix A.

7The step by step procedure adopted for analysis of the prestressed beam is as follows.

1. Calculate the Total area of cross-section NA.

2. Calculate the center of gravity from top is given by CG

3. Calculate Net section modulus of the beam cross section from

a) Compression side

$$
N Z_{x t}=\left(\frac{N I_{x}}{C G}\right)
$$

b) Tension side

$$
N Z_{x b}=\frac{N I_{x}}{(D-C G)}
$$

4. Load carrying capacity

Before prestressing load carrying capacity of the beam is given by

$w=\left(\frac{\sigma_{b c} * N Z_{x t} * 8}{l^{2}}\right)$

After prestressing the load carrying capacity of the prestressed beam is the sum of

1. Load carrying capacity of the unprestressed beam and

2. Increase in load carrying capacity due to prestressing

Mathematically

$W a=\left(\frac{\sigma_{b c} * N Z_{x t} * 8}{l^{2}}\right)-p *\left(\left(\frac{1}{N A}\right)-\left(\frac{e}{N Z_{x t}}\right)\right) *\left(\frac{N Z_{x t} * 8}{l^{2}}\right)-d l$

Hence percentage increase in load carrying

$\% \mathrm{LCC}=\frac{\mathrm{Wa}-\mathrm{W}}{\mathrm{W}} \times 100$

5. 2Check for permissible stresses

1. Check for shear stress

Maximum shear force is

$V=\frac{w \times l}{2}$

Hence, Maximum shear stress is

$T=\frac{V}{t w \times d}$

For the beam to be safe in shear, $\mathrm{T}$ should be less than allowable shear stress

i.e. $0.45 \times \mathrm{Fy}$

2. Check for crippling stress

Crippling stress is

$$
C=\frac{V}{(300+h \sqrt{3}) \times t w}
$$

For the beam to be safe in crippling, $\mathrm{C}$ should be less than allowable crippling stress i.e. $0.75^{\times}$Fy
3. Check for deflection

Upward deflection due to prestressing (before application of live load)

$$
\operatorname{def} 1=\frac{p \times e \times l^{2}}{8 \times E \times I}
$$

Net downward deflection due to prestressing and live load

$$
d e f=\frac{5 \times w \times l^{2}}{384 \times E \times I}-\frac{p \times e \times l^{2}}{8 \times E \times I}
$$

For the beam to be safe in deflection, both def1 and def should be less than maximum allowable deflection6 i.e.

\section{$\frac{l}{325}$}

4. Check for bending stresses

(I) Application of concentric prestressing force

Stage 1: Before the application of live load

Bending stress in bottom fiber is

$\sigma_{b c \text { bnl }=}\left(\frac{P}{N A}-\frac{d l \times l^{2}}{8 \times N Z x b}\right)$

Bending stress in top fiber is

$\sigma_{b c \text { tnl }=}\left(\frac{P}{N A}+\frac{d l \times l^{2}}{8 \times N Z x t}\right)$

Stage 2:After the application of live load

Bending stress in bottom fiber

$\sigma_{b c \mathrm{~b}=}\left(\frac{p}{N A}-\frac{(W a+d l) \times l^{2}}{8 \times N Z x b}\right)$

Bending stress in top fiber

$\sigma_{b c}\left(\frac{p}{N A}+\frac{(W a+d l) \times l^{2}}{8 \times N Z x t}\right)$

The above relationships show that the presence of compressive prestressing force reduces the tensile flexural stress either by eliminating tension totally and inducing some compression or by permitting some tensile stress within permissible limits.

(II) Application of Eccentric prestressing force

Stage 1:Before the application of live load

Bending stress in bottom fiber

$\sigma_{b c}$ bnl $=\frac{p}{N A}+\frac{p \times e}{N Z x b_{-}} \frac{d l \times l^{2}}{8 * N Z x b}$

Bending stress in top fiber

$$
\sigma_{b c} \text { tnl }=\frac{p}{N A} \frac{p \times e}{N Z x t} \frac{d l \times l^{2}}{8 \times N Z x t}
$$

Stage 2: After the application of live load

Bending stress in bottom fiber

$$
\sigma_{b c} \mathrm{~b}=\frac{p}{N A}+\frac{p \times e}{N Z x b} \frac{(W a+d l) \times l^{2}}{8 * N Z x b}
$$

Bending stress in top fiber 


$$
\sigma_{b c \mathrm{t}=} \frac{p}{N A} \frac{p \times e}{N Z x t}+\frac{(W a+d l) \times l^{2}}{8 \times N Z x t}
$$

Here it can be observed that the dead and live loads induce tensile stresses towards the soffit. Further the compressive stress at the top fiber is substantially reduced. To elevate this, the prestressing tendon is placed eccentrically below the neutral axes. This approach induces tensile stresses at the top fiber and compressive stresses at the bottom fiber through an eccentric moment of ' $p * e$ '. In either case, the stresses calculated in the two stages should be less than allowable bending stress.

\section{RESULTS AND DISCUSSIONS}

The procedure discussed in Section was executed for all four cases within the scope of this work and the results obtained are presented in Table. 1.

\section{CONCLUSIONS}

1. Welding a plate is more advantageous over welding an angle section.

2. A maximum $\%$ increase in the load carrying capacity of about 80 can be achieved only by prestressing an ISJ, which is strengthened in compression flange by welding a plate to the top flange.

3. The material of the cross-section is effectively utilised if it is un-symmetrical.

\section{REFERENCES}

[1] N.KrishnanRaju, "PRESTRESSED CONCRETE", Tata McGraw Hill Publishing company limited, New Delhi.

[2] IS 800: 1984 (CODE OF PRACTICE FOR GENERAL CONSTRUCTION IN STEEL)

[3] DrL.M.Guptha, "PRESTRESSED STEEL STRUCTURES", Proceedings of the conference on Modern trends in steel structures.

[4] Brodka and Klobukowki, “ATOM Bridge Construction method".

[5] Vincenzo Nunziata, "PRESTRESSED STEEL STRUCTURES", proceedings of the conference on TO CONSTRUCT IN STEEL: STRUCTURE And ARCHITECTURE at Naples (3-4-5 October 1999).

[6] IS 1343: 1980, CODE OF PRACTICE FOR PRESTRESSED CONCRETE.

[7] Ph.D(Structural Engineering) Theses Work titled "PERFORMANCE OF PRESTRESSED HOMOGENOUS STEEL I - BEAMS" byP.MarkandeyaRaju under the Guidance of Prof. V.Ravindra, JNTUK, Kakinada.

\section{APPENDIX - A (Notation)}

$\mathrm{e}$

eccentricity total depth

prestressing force

center of gravity from top

Net area/Neutral axes

thickness of flange

thickness of web

width of web

clear distance between flanges

Indian Standard Equal Angle Section

Indian Standard rolled steelI-section

Area of cross-section of I-section

Area of cross-section of Angle section

distance of centroidal $\mathrm{Y}-\mathrm{Y}$ axes of the

$\mathrm{AC}$

angle section

NIx

BIx

axes.

AI

NIy

BIy

axes.

NZxt

fiber

$\mathrm{NZxb}$

fibre

dl

$1 / \mathrm{r}$

$\mathrm{sbc}$

$\mathrm{Wa}$

beam

w

beam

$\%$ LCC

$\mathrm{V}$

$\mathrm{T}$

C

h

of the flange

EI

def1

def

$\sigma_{b c \text { bnl }}$

$\sigma_{b c \text { tnl }}$

$\sigma_{b c} \mathrm{~b}$

$\sigma_{b c \mathrm{t}}$
Net moment of inertia about X-X axes.

Moment of inertia of I-section about X-X

Moment of Inertia of the angle section

Net moment of inertia about Y-Y axes.

Moment of inertia of I-section about X-X

Net section modulus about $\mathrm{X}-\mathrm{X}$ axes at top

Net section modulus about $\mathrm{X}-\mathrm{X}$ axes at top

dead load

slenderness ratio

permissible bending compressive stress

Load carrying capacity of theprestressed

Load carrying capacity of the unprestressed

$\%$ increase in load carrying capacity

maximum shear force

maximum shear stress

crippling stress

depth of the root of the fillet from the top

Flexural rigidity

upward deflection due to prestressing alone net deflection

stress at bottom fiber at transfer

stress at top fiber at transfer

stress at bottom fiber at working loads

stress at top fiber at working loads 


\section{TABLES}

Table. 1 Results for all the four cases

\begin{tabular}{|l|l|l|l|l|l|}
\hline & $\begin{array}{l}\text { CG from bottom } \\
(\mathrm{mm})\end{array}$ & $\begin{array}{l}\text { NA } \\
(\mathrm{mm} 2)\end{array}$ & $\begin{array}{l}\text { LCC (with PSF) } \\
\mathrm{kN} / \mathrm{m}\end{array}$ & $\begin{array}{l}\mathrm{dl} \\
(\mathrm{kN} / \mathrm{m})\end{array}$ & $\begin{array}{l}\text { \% increase in LCC } \\
\text { w.r.t un-prestressed beam } \\
(\mathrm{MPa})\end{array}$ \\
\hline CASE 1 & 300 & 18486 & 53.94 & 1.42 & 18.11 \\
\hline CASE 2 & 300 & 20758 & 68.51 & 1.598 & 17.41 \\
\hline CASE 3 & 317.66 & 19622 & 63.26 & 1.5102 & 29.49 \\
\hline CASE 4 & 404.8 & 28119 & 113.803 & 2.163 & 79.64 \\
\hline
\end{tabular}

\section{FIGURES}

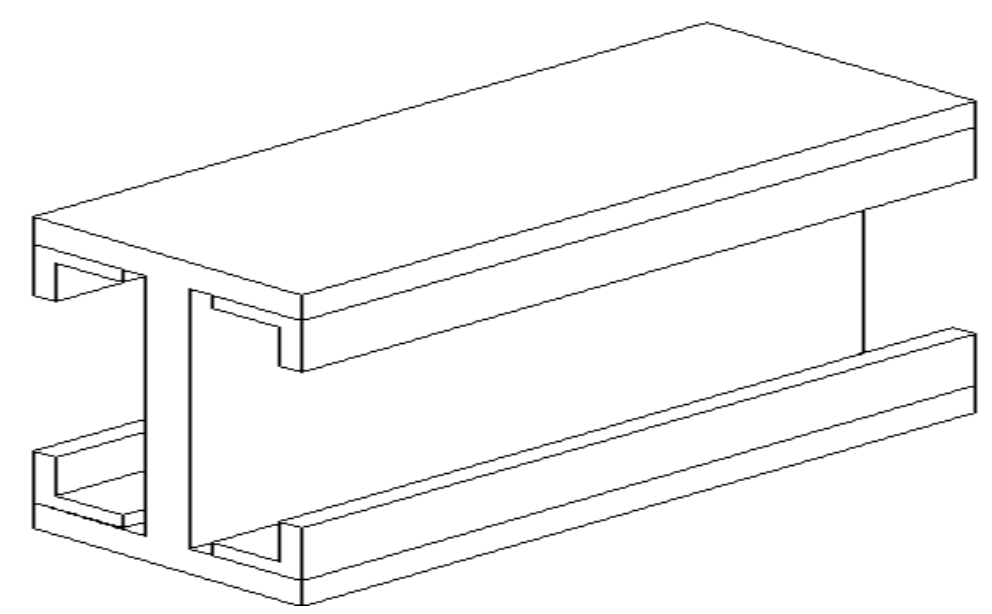

Fig 1. 3D View of an I-section welded with 4-Angle sections

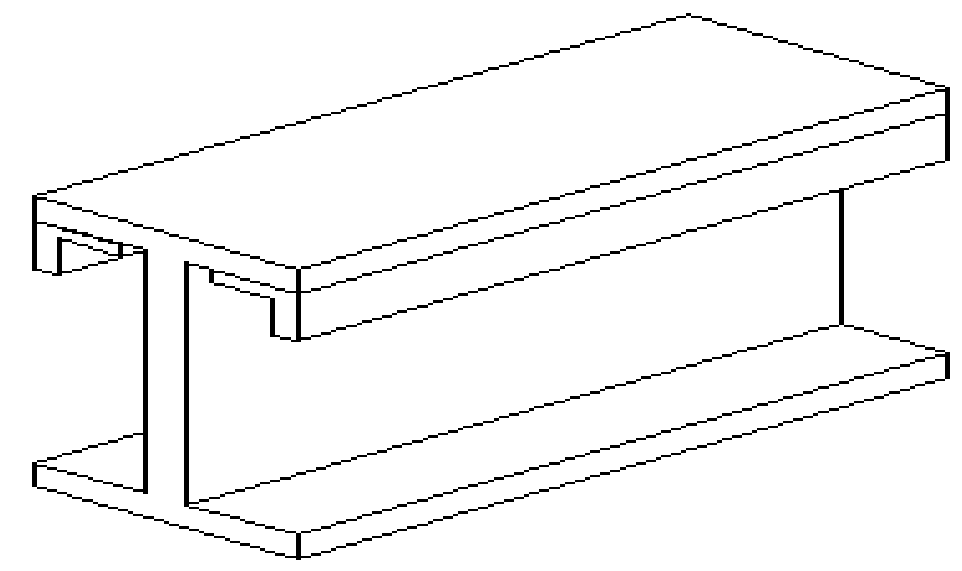

Fig. 2. 3D View of an I-section welded with 2-Angle sections

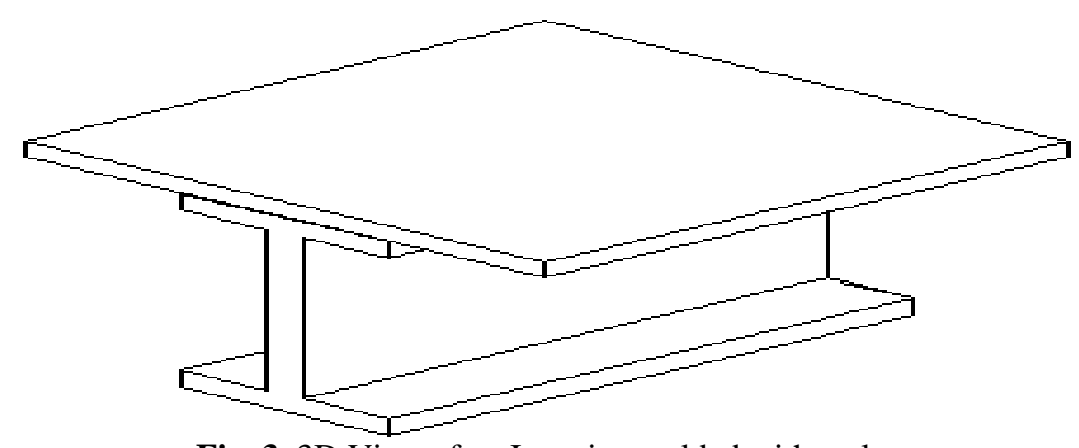

Fig. 3. 3D View of an I-section welded with a plate 


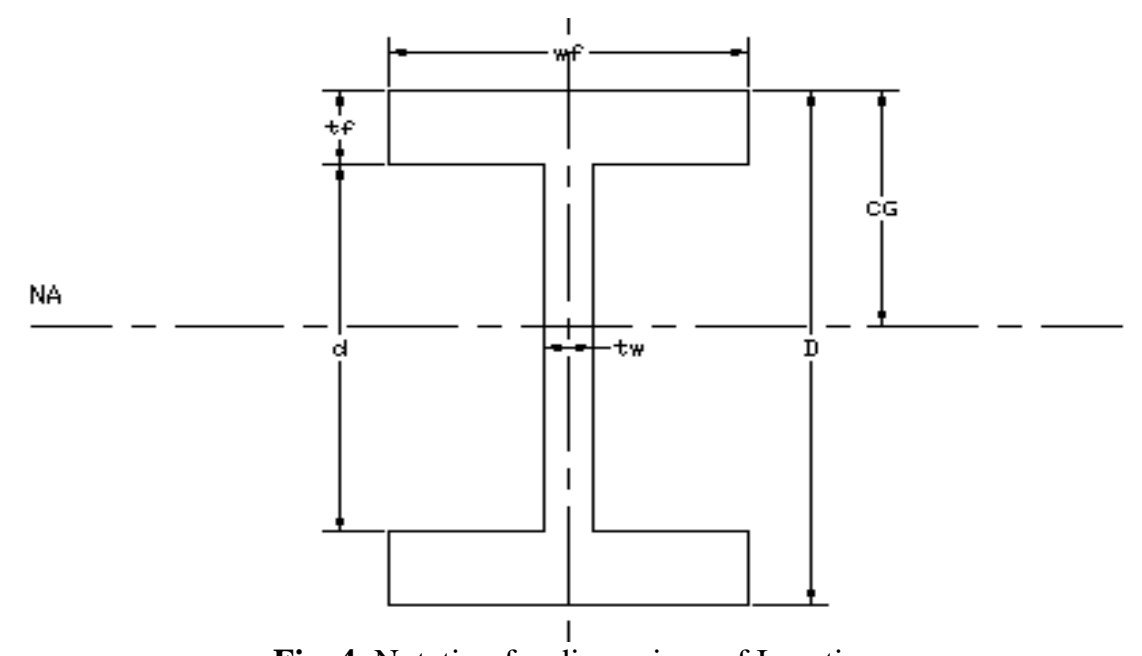

Fig. 4. Notation for dimensions of I-section

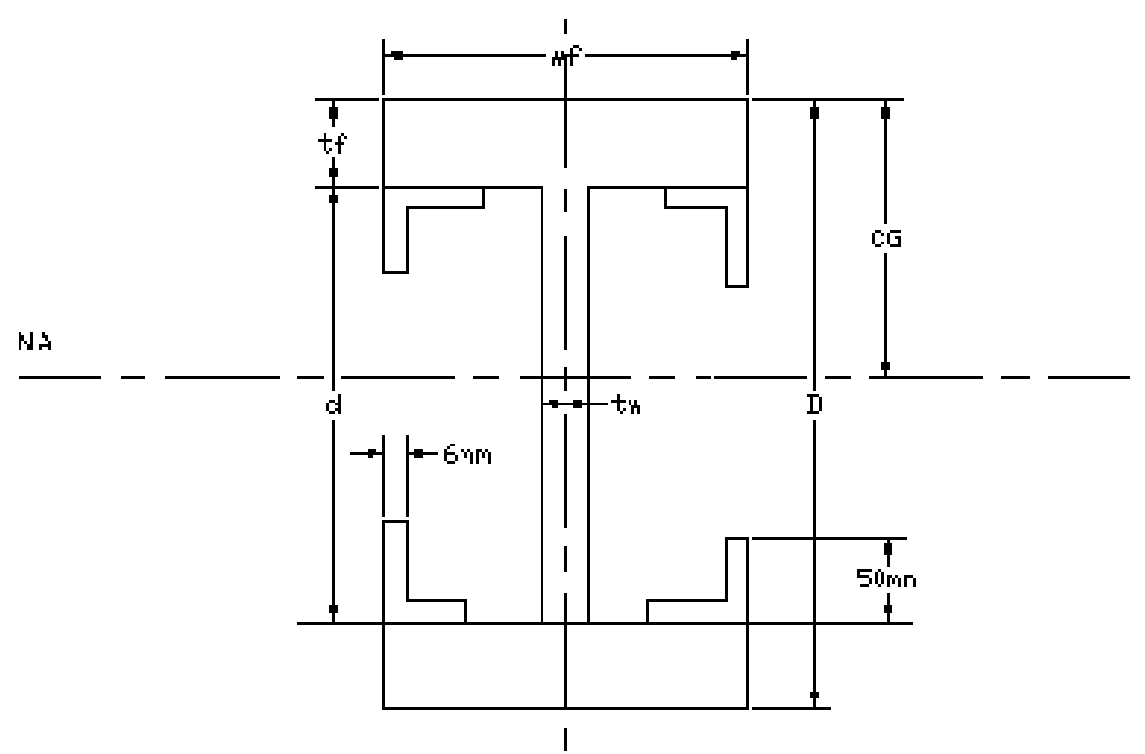

Fig. 5. Notation for dimensions of I-section welded with 4-angles

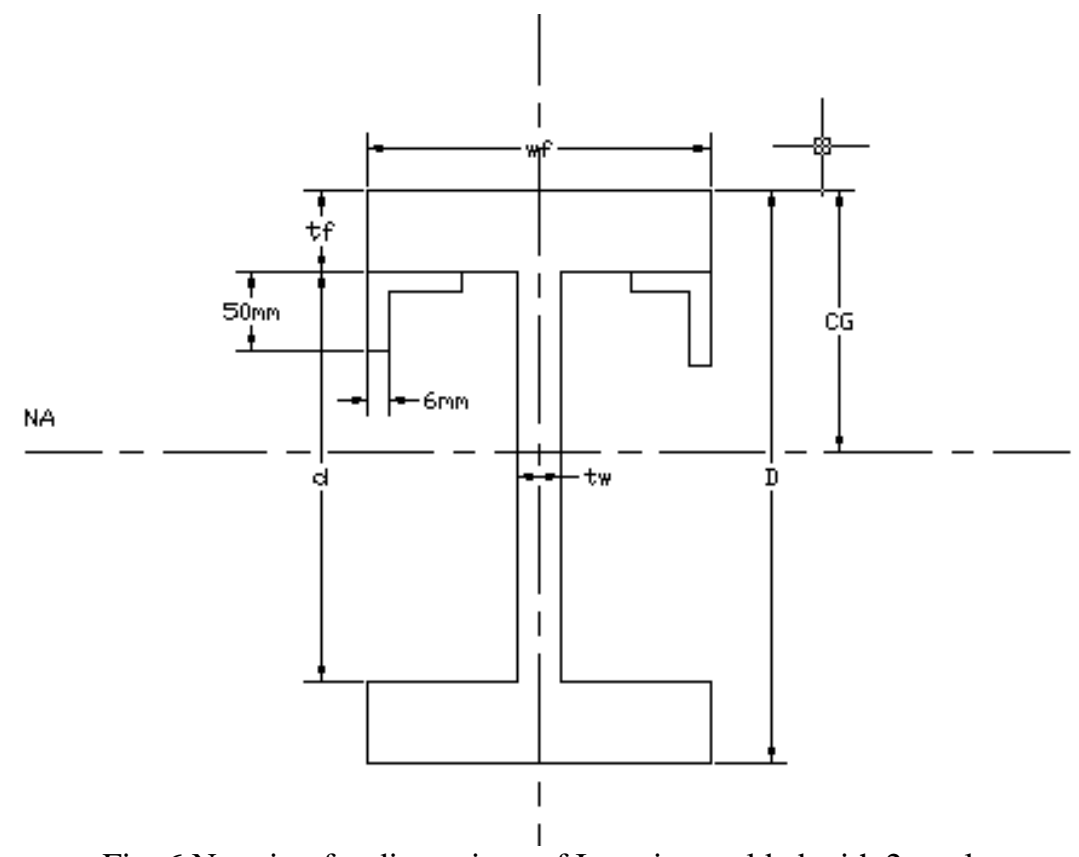

Fig. 6 Notation for dimensions of I-section welded with 2-angles 


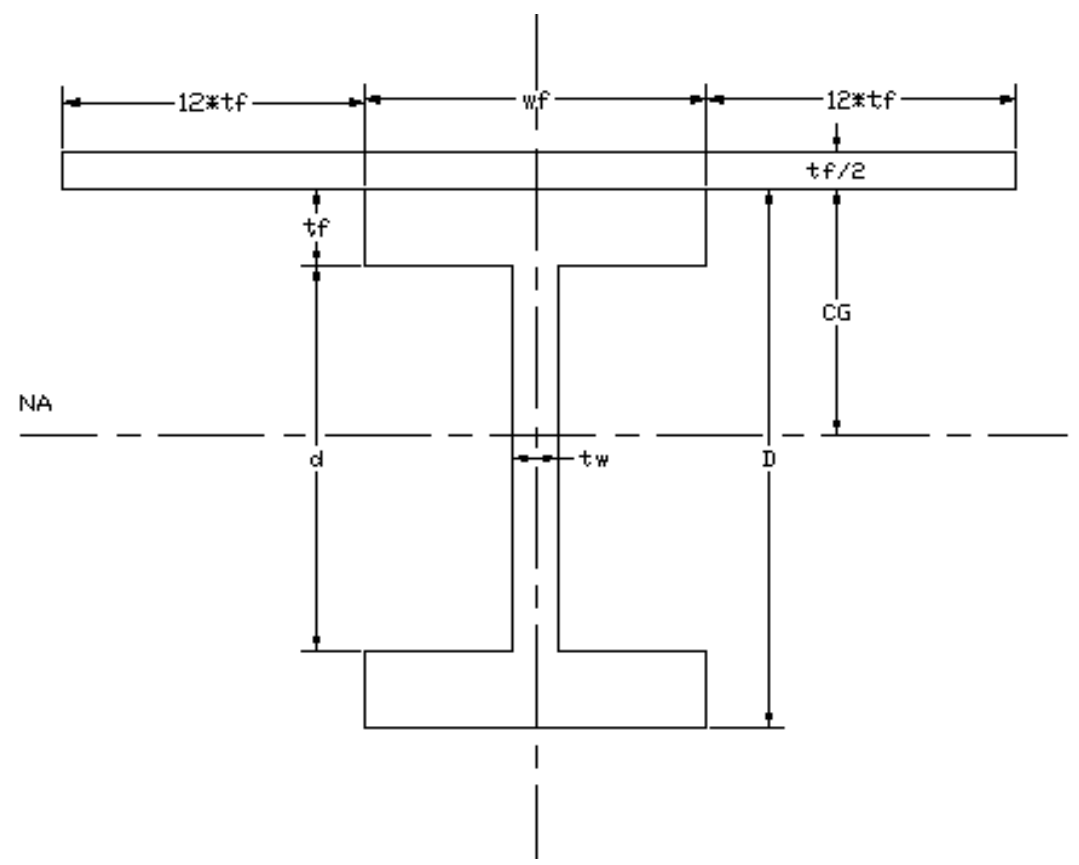

Fig. 7. Notation for dimensions of I-section welded with a plate 